\title{
Design and Development of a Novel Wheelchair with Lifting and Flattening Capabilities
}

\section{Dr. Jahangir Ansari, Virginia State University}

Jahangir Ansari is Associate Professor of Manufacturing Engineering at Virginia State University. He received his M.S. degree in Mechanical Engineering in 1979 and Ph. D. degree in Mechanical Design and Production Engineering in 1983 both from Seoul National University. He joined the faculty at VSU in 2002. His research interests include Structural Vibration, FEM, CAD/CAM/CAE, and Virtual Manufacturing. 


\title{
Design and Development of a Novel Wheelchair with Lifting and Flattening Capabilities
}

\begin{abstract}
:
Autonomy in the area of mobility has always been highly valued, but is sometimes impaired by a disability. In many cases, this results in reliance on some form of external supporting mechanism. Wheelchair users may encounter a variety of obstacles in their daily activities based on their limitations. An optimum quality of life can be achieved through more freedom in mobility. The purpose of this project is to design and build a manual wheelchair equipped with assistive flattening and lifting mechanisms to elevate the user to a target level.

The mechanism is based on a scissor lift connected to the respective footrest, seat, and backrest of the wheelchair. The unique functionality provided includes reclining and lifting the user to the desired bed level and giving the rolling capability for the user to move to and from the bed with ease. The components of the scissor lift are designed and a detail kinematic analysis of the mechanism is performed and simulated using Siemens-NX software package. The work is conducted by a team of three senior students of the manufacturing engineering (MANE) program at Virginia University as their senior project. A scaled to half size of the designed mechanism was fabricated and tested. The functionality of the both lifting and flattening mechanisms were successfully achieved.
\end{abstract}

\section{Introduction:}

Manufacturing engineering students at Virginia State University develop their skills for the various elements of the design process throughout the curriculum, culminating in their senior design project I and II courses during their senior year.

The program offers at least six core courses in which engineering design is included. These courses are: Engineering Graphics, CAD/CAM, Manufacturing Automation, Simulation, Quality Control, and Manufacturing Design Implementation. These six major courses and some other courses distributed throughout the curriculum include elements of design that adequately define an integrated design experience for the students in the program. During their senior year, students also may gain additional design experience in their chosen ENGR/MANE elective courses such as Special Topics. Most of these courses include labs, and students are assigned to work on design projects to satisfy the student learning outcomes ${ }^{1}$.

\section{Senior Design Course Overview:}

MANE students take MANE 461 and 462 (two credit hours each) senior design courses in their senior year as a capstone to accomplish all aspects of the design requirements. Depending on the nature of the selected projects, they may be teamed with computer engineering students. The principles of the design and project planning and control processes are taught by the projects coordinator faculty through the entire life of the projects. Each project advisor faculty advises one or two teams on designing and prototyping their project(s). Manufacturing students mostly are assigned to select topics in product/system design and realization projects, while being required to incorporate the following tasks: 
- Need recognizing

- Problem defining

- Project planning

- Design conceptualization

- Design alternatives

- Alternative selection

- Communicating the design

- Design implementation

The projects are done in teams of no more than four students to maintain the following objectives:

- Understand constraints (Time, Budget, Equipment limitations, Size and Material )

- Learn to work in a given time frame

- Learn to work in a team environment

- Learn to communicate effectively

- Enhance design and management skills

By the end of the project, students are expected to demonstrate the following skills:

- Design Skills-Through working on their project, the students enhance this skill by going through the complete product development process, and by developing and meeting a schedule and budget constraints.

- Team Skills- Through working as a team, the students enhance this skill by combining their strengths and efforts to work effectively to complete their team project.

- Communication Skills- During the life of project, students are required to meet, discuss, and submit their weekly progress report. Periodically, they are responsible to submit a comprehensive report and give a clear and informative oral presentation on the work they have done.

At the last week of each semester, the department sponsors "Senior Design Presentation Day", during which all the senior design projects are presented. The projects are evaluated by the engineering faculty and invited Industrial Advisory Committee members. The evaluations also consider how well the group worked together, presented results, and incorporated both technical and non-technical considerations in the design.

\section{Senior project:}

The development of special products for the elderly and disabled groups can significantly enhance their quality of life. Literature studies show the development process of wheelchairs; from manual, electric, and motor wheelchairs to smart wheelchairs. Due to their lower cost and simpler design, manual wheelchairs are commonly used. However, the user may face more challenges due to a higher physical strength requirement and caretaker dependence ${ }^{2,3}$.

"Design and build an assistive inclining and lifting mechanisms attachment to manual wheelchairs to elevate the user to a target level" was selected as the topic of a senior design project for a team of three MANE students. The proposed device is based on the integration of incliner and lift mechanisms connected to the respective frame of a standard manual wheelchair. The unique functionality of the device provides lifting and rolling capability to the user to move to and from a 
bed with minimum effort. The proposed design will meet the needs of elderly and disabled people with mobility issues.

In this project, students use their knowledge and skills of solid modeling to visualize their conceptual ideas, and design and simulate the final product. The team fabricate all the parts in a half scale, assembled a prototype, and tested for functionality of the final design too.

\section{Design Methodology:}

The mechanical setup of the device includes an assembly of a top frame, a back rest, a foot rest, and a base frame. The base frame of the device can be attached to the frame of the manual wheelchair by adjustable clamps. The lift mechanism is fixed between the two frames in such a way that the top frame can move vertically by means of a lifting mechanism such as a scissor lift. The device design and construction contains two main parts, the lift mechanism and the incliner mechanism.

The approach to developing the device design was to produce a set of target specifications. Based on the target specifications, new concept designs were generated, and the final concept selection was made using selection matrices. The chosen concept was further developed to a detail that could be compared to the reference design criteria. As a final step, an evaluation of the final concept was performed using kinematics and structural performance and cost analyses. In this study the entire project is divided into three main phases:

\section{Phase I: Design Development Process}

\section{Problem Definition:}

Wheelchair users may encounter a variety of obstacles in their daily activities based on their limitations. Providing more freedom in mobility will lead to a more optimum quality of life. The purpose of this project is to design and build an assistive device equipped with flattening and lifting mechanisms, attached to a manual wheelchair, elevating the user to a target level.

\section{Design Requirements:}

The mechanism is based on combination of incliner and lift mechanisms connected to the respective frame of a standard manual wheelchair. The unique functionality provided includes reclining and lifting the user to the desired bed level and giving the user the rolling capability to move to and from the bed easily. The requirements of the device are to lift the maximum load of $200 \mathrm{lb}$ up to and from the highest position of 12 inches. Furthermore, the device is required to have a maximum operation time of 1 minute. Due to the limited space, the foot print of the device must be within the seat size of a normal wheelchair. Additionally, it must also hold its position when the power is off, and most importantly, the device must be safe to use. These requirements are listed in Table 1.

Table 1. Design Requirements

\begin{tabular}{|l|l|l|l|}
\hline Requirement -Lift & Value & Requirement -Incliners & Value \\
\hline Lifting Load & $200 \mathrm{lb}$ & Backrest Inclining Angle & $90 \mathrm{deg}$ \\
\hline Lifting Height & $12 \mathrm{in}$. & Footrest Inclining Angle & $90 \mathrm{deg}$ \\
\hline
\end{tabular}




\begin{tabular}{|l|l|l|}
\hline Max lift time & 1 min & Operation- Manual \\
\cline { 1 - 2 } Foot Print & $\begin{array}{l}20 \text { in. } x 20 \\
\text { in. }\end{array}$ & \\
\cline { 1 - 2 } Max Compact Height & 6 in. & \\
\cline { 1 - 2 } $\begin{array}{l}\text { Operation- } \\
\text { Electric/Manual }\end{array}$ & \\
\hline \multicolumn{2}{|c|}{ Additional Requirements } \\
\hline Must be safe \\
\hline Hold position firmly \\
\hline Operable without/with minimum assistance \\
\hline
\end{tabular}

\section{Phase II: Concepts Generation}

After brainstorming and literature studies of the current designs, the team created the solid model and assembly of three lifts and three incliners' concepts to visualize their design alternatives. These alternatives are shown in Figure 1.

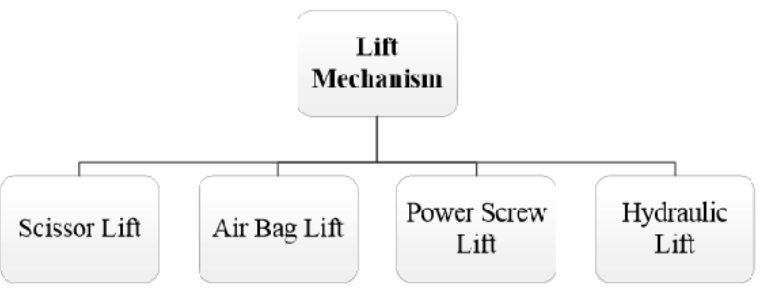

(a)

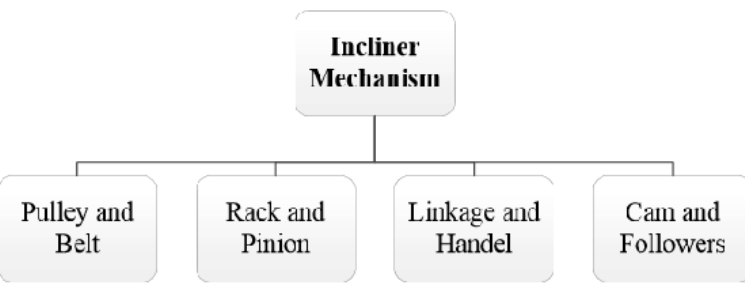

(b)

Figure 1- Design alternatives: (a) Lift mechanism (b) Incliner mechanism

\section{Lifting Mechanisms}

The three lifting mechanisms that were considered for our design alternatives were scissor lift, inflating tube (air bag) lift, and power screw lift. All these lifts can be suited for our targeted wheelchair users.

\section{Scissor Lift}

The scissor lift contains multiple stages of cross bars which can convert a linear displacement between any two points on the series of cross bars into a vertical displacement multiplied by a mechanical advantage factor. This factor (actually a disadvantage) depends on the position of the points chosen to connect an actuator and the number of cross bar stages. The amount of force required from the actuator is also amplified, and can result in very large forces required to begin lifting even a moderate amount of weight if the actuator is not in an optimal position. Actuator force is not constant, since the load factor decreases as a function of lift height.

\section{Air Bag Lift}


Air Lifting Bags are pneumatic devices designed to perform mechanical functions such as pushing, pressing, and lifting. They are normally inflated with air and are easy to integrate into conventional mechanical systems. Depending on the application, they are manufactured in different shapes, sizes and capacities with the following advantages.

- Compact when empty

- Perfect distribution of thrust

- Small overall dimensions

- Adaptable to various types of surfaces

- High lifting force

- None contaminating

- Very low maintenance

\section{Power Screw Lift}

Power screws convert rotational motion into linear motion. An electric motor and gearbox would be used to power the nut that would cause the screw to lift the desired load. The electric motor would drive the nut from the bottom of the lift and a thrust bearing would hold the nut on the top of the frame. The screw would be fasten to the sliding frame and would pull the lift up when the motor turns the sprocket mounted nut by means of a chain system.

a) Rotating screw with travelling nut

Driven by precision worm gearing (screw keyed to the worm wheel), the screw rotates and the travelling nut travels along it. The travelling nut carries the load.

b) Rotating nut with travelling screw

Driven by chain (nut keyed to the sprocket), the nut rotates and the travelling screw travels along its axis. The travelling screw carries the load. The three lift mechanism concepts are illustrated in Figure 2.

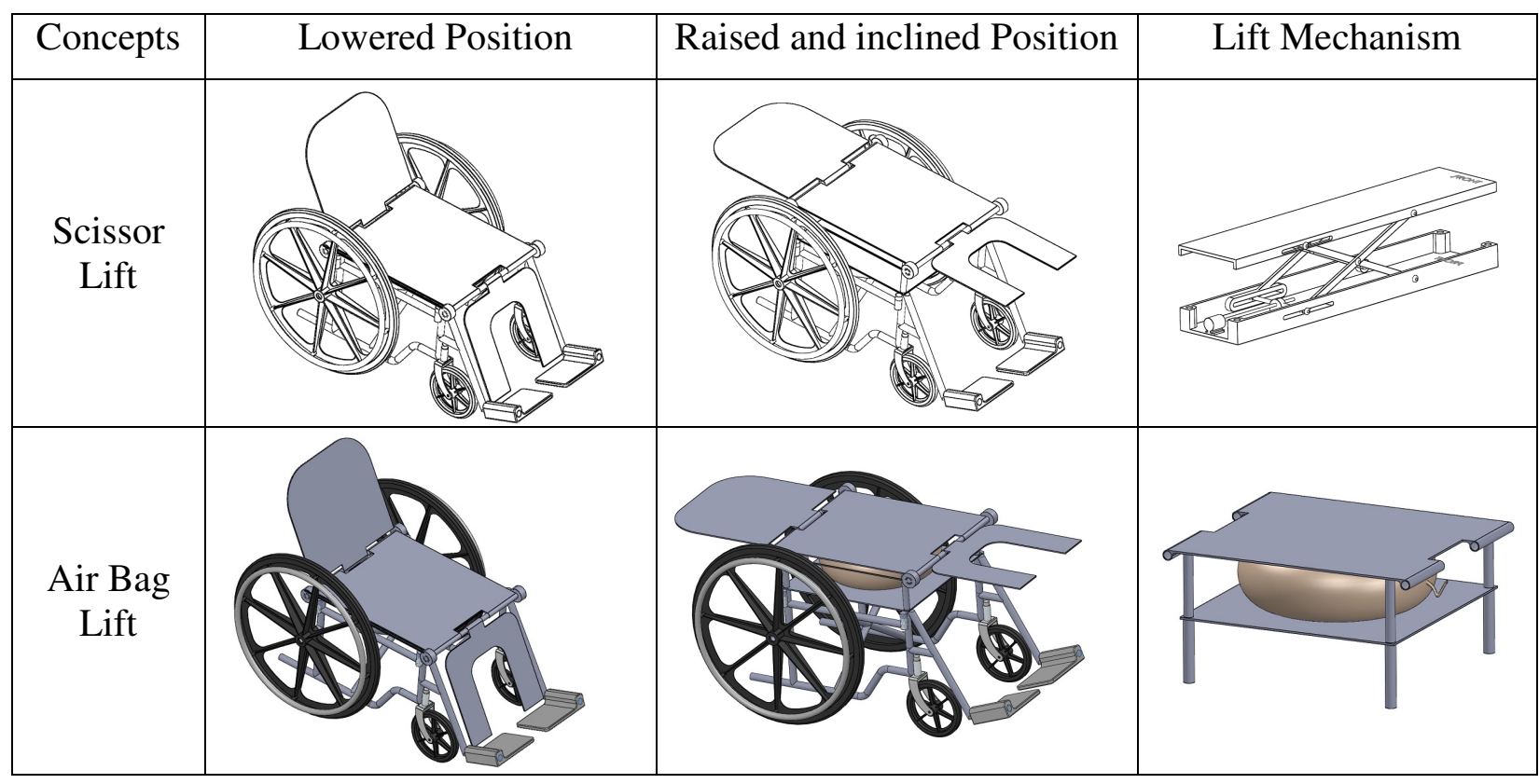




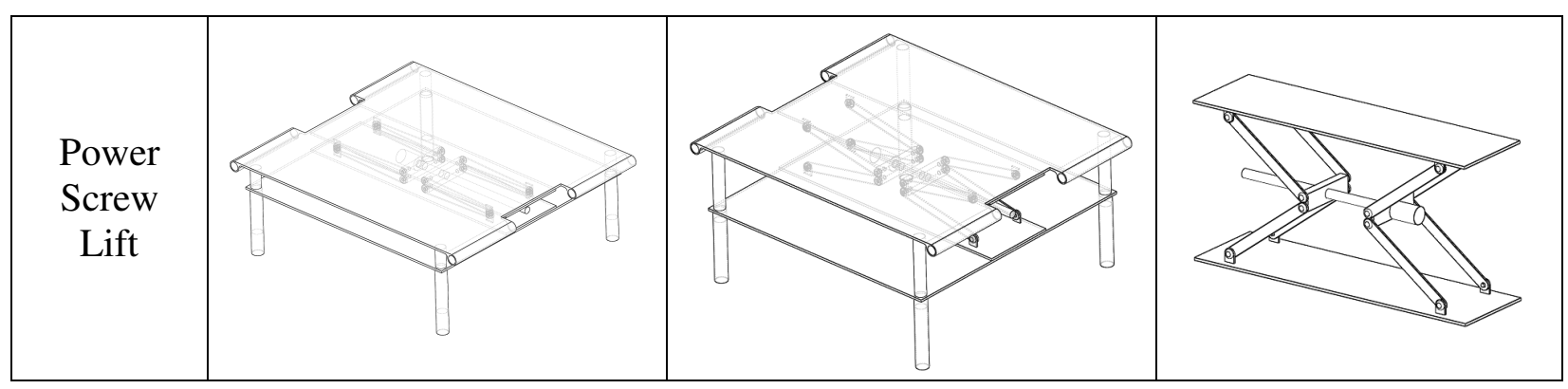

Figure 2- Lift mechanism concepts

The three separate lifting mechanisms were considered in the concept evaluation process for the final design selection. They were evaluated based on safety, cost, ease of operation, and simplicity as show in table 2 .

Table 2. Lift mechanism concepts evaluation

\begin{tabular}{|l|c|c|c|}
\hline \multirow{2}{*}{$\begin{array}{c}\text { Evaluating } \\
\text { Criteria }\end{array}$} & \multicolumn{3}{|c|}{ Lift Mechanisms } \\
\cline { 2 - 4 } & Scissor & Air Bag & Power Screw \\
\hline Safety & 4 & 5 & 5 \\
\hline Cost & 3 & 5 & 3 \\
\hline Ease of operation & 3 & 4 & 3 \\
\hline Simplicity & 3 & 5 & 4 \\
\hline & 13 & 19 & 15 \\
\hline
\end{tabular}

\section{Incliner Mechanisms}

In our design both footrest and backrest are attached to both ends of the respective seat. The design requires the push/pull motion of a handle by user to be converted to rotational motion of both footrest and backrest simultaneously. The two mechanisms that were considered for our design alternatives were pulley and belt, and four-bar linkage as illustrated in Figure 3.

\begin{tabular}{|c|c|c|c|c|}
\hline Concepts & Seating Position & Lay down Position & Incliner Mechanism \\
\hline $\begin{array}{c}\text { Pulley and } \\
\text { Belt } \\
\text { Linkage }\end{array}$
\end{tabular}

Figure 3- Incliner mechanism concepts 


\section{Phase III: Product Development}

Utilizing the concepts developed in phase II, the designs are refined to the point that the prototype can be made and tested. In this phase, the detail drawings of the all components and assemblies are developed. Performance evaluation, cost estimation, design for manufacturing, and design for assembly are performed in this phase as well. The final design of both lift and incliner mechanisms and the prototype of the final product are shown in Figures 4 and 5 respectively.

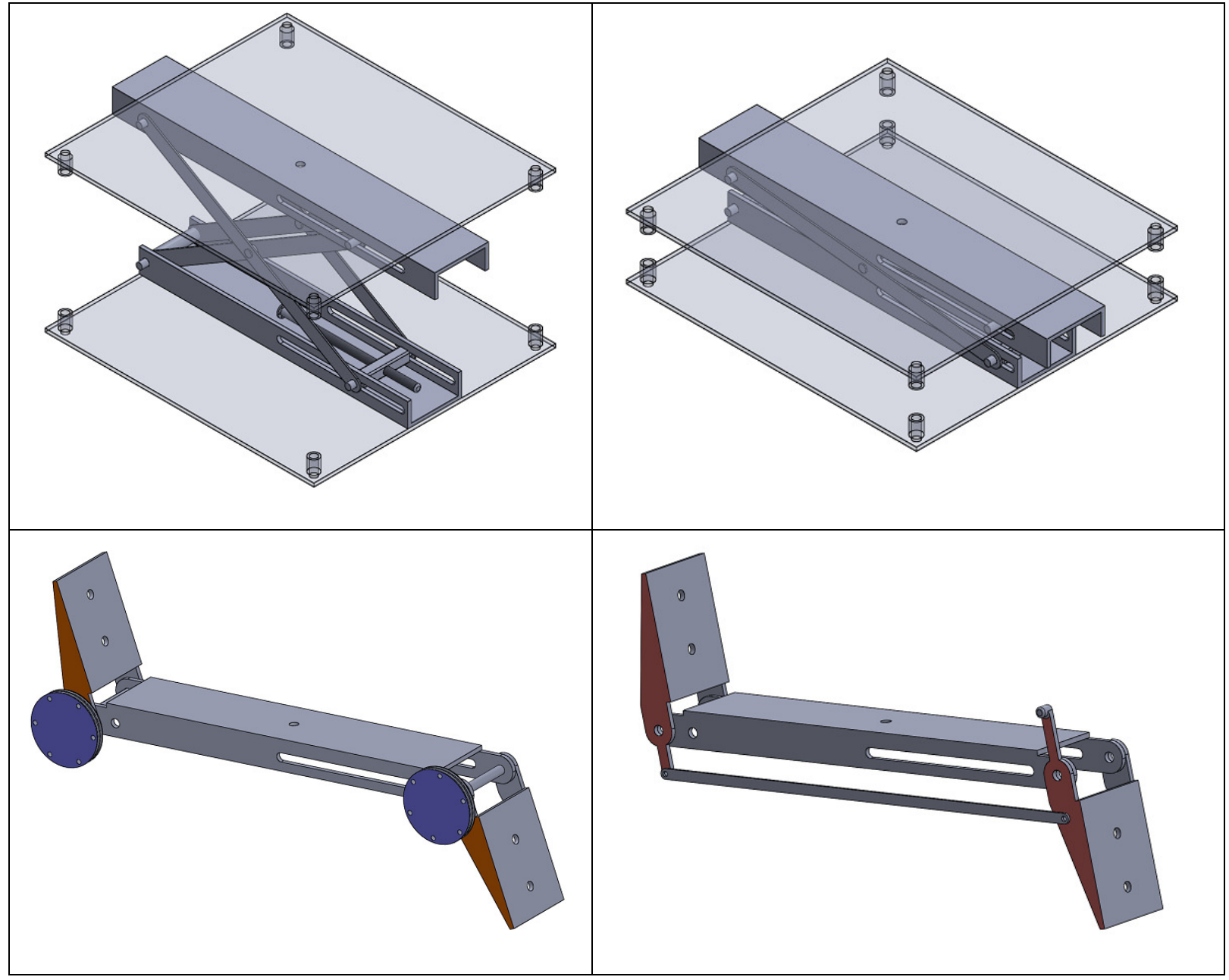

Figure 4- Final Design of Lift and Incliner Mechanisms 


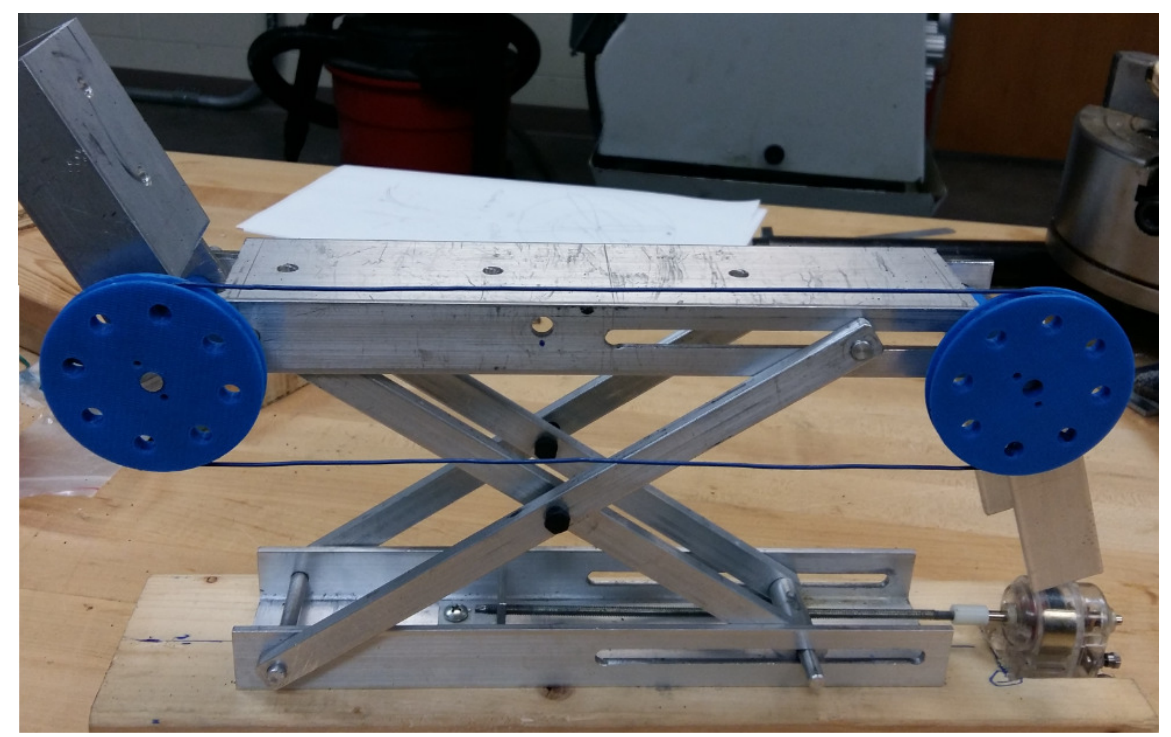

Figure 5- Prototype of Final Product

\section{Results and Discussion:}

The validity of the designed mechanisms was achieved by creating solid models of all the components and simulating the assembled model of the device by CAD software. In this manner, the entire system could be simulated and refined for further improvement and optimization. The kinematic analyses of the system show that the dimensional characteristics of all components have fulfilled the functional performances of the device. The fabrication of the prototype completed and functionality was successfully tested.

The main result of this project shows that it is possible to reduce the device's mass without compromising the safety, cost or functionality performance of the mechanisms. More specifically, it is possible to achieve this goal by redevelopment of the manual wheelchair equipped with adjustable seat system with lift and flattening capabilities for home use.

\section{Students' Learning Outcomes Assessment:}

After the completion of their project, students are required to write a comprehensive final report and give a clear and informative oral presentation elaborating on the work they have done throughout the project.

The students' learning outcomes are measured by the MANE faculty using the following performance indicators.

- Demonstrate ability to select appropriate tools in a design process

- Demonstrate clear and sound reasoning preparing for a design solution

- Demonstrate effective contribution in achieving the project/team goal(s)

- Demonstrate effective collaboration by taking responsibility

- Demonstrate quality interactions with the other team members

- Demonstrate ability to locate and use appropriate resources to solve problems. 
- Demonstrate ability in writing and graphical communication skills required by engineering profession

- Demonstrate ability to write clear and effective papers and reports including figures, plots, and tables

- Demonstrate oral presentation skills appropriate in engineering profession

- Demonstrate knowledge of selecting tools in a manufacturing design and implementation process

- Demonstrate effective use of practical and analytical techniques in engineering practice

Students presented their project to the MANE faculty on last day of the semester (Students' Senior Projects Presentation Day). The result of the assessment is shown in Figure 6 below.

\section{Students Learning Assessment}

1. Demonstrate ability to select appropriate tools...

2. Demonstrate clear and sound reasoning...

3. Demonstrate effective contribution in achieving...

4. Demonstrate effective collaboration by taking...

5. Demonstrate quality interactions with the other...

6. Demonstrate ability to locate and use...

7. Demonstrate ability in writing and graphical...

8. Demonstrate ability to write clear and effective...

9. Demonstrate oral presentation skills appropriate..

10. Demonstrate an ability to use engineering..

11. Demonstrate effective use of practical and...

$\begin{array}{lllllllll}0 & 0.5 & 1 & 1.5 & 2 & 2.5 & 3 & 3.5 & 4\end{array}$

\section{Conclusion:}

In conclusion, performing the project gives students the chance to develop their creativity, critical thinking, and hands-on skills in the areas of their interest. They learn to work effectively as a team to complete their project in a timely manner by combining their different strengths and efforts.

Through working on their project, students enhance their design skill by going through the complete product development process. They learn to meet deadlines, and work within time and budget constraints. They also learn to communicate and deal with other team members, and improve the team's efficiency. In the peer evaluation process during the project presentations, they learn from each other while commenting constructively.

The following are some opinions of the team members: 
- An engineer must be able to analyze and understand time and resources before he/she can determine what can be produced. I learned this as we scoped down from our original idea.

- An engineer must hold documentation as a priority. Careful documentation can not only help give validity to a project, but also make the creation of final reports easy.

- It is important to give the same amount of effort to the first half of a project that you do when it is crunch time. An engineer must strive to finish a project in the shortest amount of time that still guarantees efficiency.

- Meetings are important even when there are no tough decisions to make. Meetings allow sharing of ideas which can lead to the growth of more ideas. It is important to meet frequently and discuss direction.

- I have learned that the first solution that you come up with is never the best solution; you have to test many alternatives before finding the right solution.

- Engineers create problems that they then find solutions for; each solution can produce another problem to be addressed, which is why product designs are always improving.

- Biggest outcome would be extensive research and development utilized by all team members.

- Cooperativeness and adaptability of the team members to accomplish tasks.

\section{Acknowledgements:}

This work was supported through a grant from National Science Foundation to Virginia State University (HBCU-UP Grant No. HRD-1036286) 


\section{Bibliography:}

(1) J. Ansari, "DESIGN EXPERIENCE IN A MANUFACTURING ENGINEERING PROGRAM", Proceedings of the 2010 ASEE Annual Conference and Exposition.

(2) Zheng, G. Q., Dong, T., \& Deng, Y. W. (2016). Theoretical Model of Special Product Design for the Elderly. Art and Design Review, 4, 1-7. http://dx.doi.org/10.4236/adr.2016.41001

(3) Xiang, Z.R., Zhi, J.Y., Dong, S.Y. and Xu, B.C. (2016) Study on Characteristics of the Wheelchair-User Combination. Journal of Biosciences and Medicines, 4, 9-17. http://dx.doi.org/10.4236/jbm.2016.46002 